\title{
Clinical Study \\ Efficacy of Levofloxacin Based Triple and High-Dose PPI-Amoxicillin Dual Eradication Therapy for Helicobacter pylori after Failures of First- and Second-Line Therapies
}

\author{
Kenichiro Okimoto, ${ }^{1}$ Makoto Arai, ${ }^{1}$ Keiko Saito, ${ }^{1}$ \\ Shoko Minemura, ${ }^{1}$ Daisuke Maruoka, ${ }^{1}$ Tomoaki Matsumura, ${ }^{1}$ Tomoo Nakagawa, \\ Tatsuro Katsuno, ${ }^{1}$ Chisato Ishii, ${ }^{2}$ Shota Murata, ${ }^{2}$ Masaharu Watanabe, \\ Fumio Nomura, ${ }^{2}$ and Osamu Yokosuka ${ }^{1}$
}

${ }^{1}$ Department of Gastroenterology and Nephrology, Graduate School of Medicine, Chiba University, Inohana 1-8-1, Chiba City 260-8670, Japan

${ }^{2}$ Department of Clinical Laboratory, Chiba University Hospital, Japan

Correspondence should be addressed to Makoto Arai; araim-cib@umin.ac.jp

Received 10 September 2014; Revised 14 November 2014; Accepted 1 December 2014; Published 17 December 2014

Academic Editor: Vikram Kate

Copyright (C) 2014 Kenichiro Okimoto et al. This is an open access article distributed under the Creative Commons Attribution License, which permits unrestricted use, distribution, and reproduction in any medium, provided the original work is properly cited.

Objectives. The aim of this study was to investigate and compare the eradication rate of Helicobacter pylori as the third-line triple therapy with rabeprazole (RPZ) + amoxicillin (AMPC) + levofloxacin (LVFX) and high-dose RPZ + AMPC. Methods. 51 patients who failed Japanese first-line (proton pump inhibitor (PPI) + AMPC + clarithromycin) and second-line (PPI + AMPC + metronidazole) eradication therapy were randomly assigned at a 1:1 ratio to one of the following third-line eradication groups: (1) RAL group: RPZ 10 mg (b.i.d.), AMPC 750 mg (b.i.d.), and LVFX 500 mg (o.d.) for 10 days; (2) RA group: RPZ 10 mg (q.i.d.) and AMPC $500 \mathrm{mg}$ (q.i.d.) for 14 days. Patients who failed to respond to third-line eradication therapy received salvage therapy. Results. The rates of eradication success, based on intention to treat (ITT) analysis, were $45.8 \%$ in the RAL group and $40.7 \%$ in the RA group. The overall eradication rates were $73.9 \%$ in the RAL group and $64.0 \%$ in the RA group. There was no significant difference between the two groups. Conclusions. The third-line triple therapy with RPZ, AMPC, and LVFX was as effective as that with high-dose RPZ and AMPC.

\section{Introduction}

Helicobacter pylori (H. pylori) is a Gram-negative bacillus that inhabits the gastric mucosa and mucus. H. pylori infection is now known to be a risk factor of a wide range of diseases, such as atrophic gastritis, gastroduodenal ulcer, mucosaassociated lymphoid tissue (MALT) lymphoma, gastric cancer, and idiopathic thrombocytopenic purpura (ITP) [1-4]. Furthermore, the recurrence of early gastric cancer after its endoscopic resection was reported to be reduced to almost one-third if $H$. pylori was successfully eradicated [5]. In Japan
150,000 deaths from gastric cancer will be prevented over 5 years if all $H$. pylori is eliminated [6].

The first-line eradication therapy of H. pylori in Japan is triple therapy, consisting of a proton pump inhibitor (PPI), amoxicillin (AMPC), and clarithromycin (CAM). This regimen has been covered by the national health insurance system since December 2000. However, due to the increase of CAM-resistant $H$. pylori strains, the eradication rate of first-line therapy is reported to be as low as 75\% [7]. Secondline eradication therapy, consisting of PPI, AMPC, and metronidazole (MNZ), has been approved in Japan for those 
who fail the first-line therapy. The eradication rate of the second-line therapy has been reported to be around 90\% $[8,9]$. These results indicate that about $3 \%$ of $H$. pylori positive patients fail in both first- and second-line therapy. From 2013, the eradication treatment for $H$. pylori infection with chronic gastritis was covered by the national health insurance in Japan. As the number of the patients who are eligible for the eradication of $H$. pylori is estimated to be increasing, it is becoming more important to establish standard thirdline eradication therapy. The guidelines of the Japanese Society of Helicobacter Research suggest PPI + AMPC + levofloxacin (LVFX) or high-dose PPI + AMPC as the thirdline eradication regimen in 2009. In the former regimen, the rate of eradication was reported to be $43.1-70.0 \%$ if it was used as third-line therapy $[10,11]$. In the latter regimen, the rate of eradication was reported to be $54.3 \%$ if it was used as third-line therapy [11]. Until now, which regimen is more effective for third-line eradication therapy has not been clarified sufficiently. The aim of this study was to investigate and compare the eradication rate of third-line triple therapy with rabeprazole $(\mathrm{RPZ})+$ AMPC + LVFX to high-dose RPZ + AMPC which were suggested in the guidelines of the Japanese Society of Helicobacter Research in 2009.

\section{Methods}

2.1. Study Design and Patients. This was a prospective, randomized, controlled study conducted in Chiba University Hospital. From June 2011 to June 2013, patients who failed Japanese first-line (PPI + AMPC + CAM) and second-line $(\mathrm{PPI}+\mathrm{AMPC}+\mathrm{MNZ})$ eradication therapy were randomly assigned to one of the following third-line eradication groups at a 1:1 ratio using random number tables: (1) RAL group: RPZ 10 mg (b.i.d.), AMPC 750 mg (b.i.d.), and LVFX $500 \mathrm{mg}$ (o.d.) for 10 days; (2) RA group: RPZ $10 \mathrm{mg}$ (q.i.d.) and AMPC $500 \mathrm{mg}$ (q.i.d.) for 14 days. Patients (1) who had a past history of allergy to the study drugs, (2) who had severe liver dysfunction, (3) who were undergoing treatment of malignant disease, (4) who were pregnant or lactating, or (5) who were ineligible to participate in this study according to the decision of a physician were excluded from this study. The primary endpoint was to compare the eradication rate between RAL and RA group. The secondary endpoints were the safety of treatment and the efficacy of fourth-line treatment.

Before being randomized, all patients underwent upper endoscopy and we performed $H$. pylori sensitivity testing for the antibiotics (AMPC, CAM, MNZ, and LVFX). Six to twelve weeks after the end of the third-line eradication therapy, a ${ }^{13} \mathrm{C}$-urea breath test (UBT) was performed. Patients who failed to respond to third-line eradication therapy received salvage therapy as the fourth-line one. In this regimen, patients who were treated with RAL received RA (salvage RA group) and those treated with RA received RAL (savage RAL group). Six to twelve weeks after the end of the salvage therapy, $H$. pylori eradication was assessed again with UBT. During the study, blood samples were taken from the patients to analyze the cytochrome P450 2C19 (CYP2C19) polymorphism.
This study was conducted according to the principles of the Declaration of Helsinki. All participating patients gave written informed consent. The study protocol was approved by Chiba University Institutional Review Board and registered (Clinical Registration Number, UMIN000005373).

2.2. Assessment of the Presence and Eradication of H. pylori. All patients underwent UBT before third-line eradication to check for the presence of $H$. pylori. At 6-12 weeks after the third-line therapy and salvage therapy, the patients whose UBT results were negative were considered to have eradicated the infection. Before UBT, PPI, which may influence the test results, was discontinued for at least 2 weeks.

2.3. H. pylori Testing for Sensitivity to the Antibiotics. H. pylori strains were isolated from tissue samples from the gastric corpus and antibiotic sensitivity testing was performed using the E-test. The breakpoints were $1.0 \mu \mathrm{g} / \mathrm{mL}$ for ABPC, CAM, and LVFX and $8.0 \mu \mathrm{g} / \mathrm{mL}$ for MNZ. An H. pylori strain was judged resistant to the antibiotics when its minimum inhibitory concentrations (MIC) value was equal to or beyond the breakpoint.

2.4. CYP2C19 Gene Polymorphism. CYP2C19 gene polymorphism was analyzed. Genotyping of the two mutated genes was performed using the gene analysis by fluorescence correlation spectroscopy (gFCS) method with blood serum samples from the patients. The CYP2C19 gene polymorphisms were classified into three types: CYP2C19 wild type gene $\left(\mathrm{CYP} 2 \mathrm{C} 19^{*} 1\right)$ and two mutated genes (CYP2C19*2 and CYP2C19*3). Patients with $\left({ }^{*} 1 /^{*} 1\right)$ were categorized as the homogeneous extensive metabolizers (EM). Patients with $\left({ }^{*} 1 /{ }^{*} 2\right)$ or $\left({ }^{*} 1 /{ }^{*} 3\right)$ were categorized as the heterogeneous EM. And patients with $\left({ }^{*} 2 /^{*} 3\right),\left({ }^{*} 2 /^{*} 2\right)$, or $\left({ }^{*} 3 /^{*} 3\right)$ were categorized as the poor metabolizers (PM).

2.5. Adverse Events. Adverse events (AE) were evaluated by asking the patients about their condition and laboratory evaluation of liver and renal function, which was performed two weeks after the end of the third-line eradication therapy.

2.6. Statistical Analysis. Statistical analysis of the third and overall eradiation rates was performed between two groups using the chi-square test. Each parameter of the patient background was analyzed using the chi-square test or unpaired $t$ test. Adverse events were analyzed using the chi-square test. A $P$ value of $<0.05$ was considered to be statistically significant. Statistical analysis was performed by the software SPSS 16.0J (SPSS Inc., Chicago, IL, USA), with $P<0.05$ considered statistically significant.

\section{Results}

3.1. Study Patients. Fifty-one patients were enrolled in this study and the study flow of the patients is shown in Figure 1. The 51 patients were randomly assigned to the RAL group $(n=24)$ or RA group $(n=27)$ (intension to treat (ITT) analysis subjects set). Three patients in the RA group were excluded 


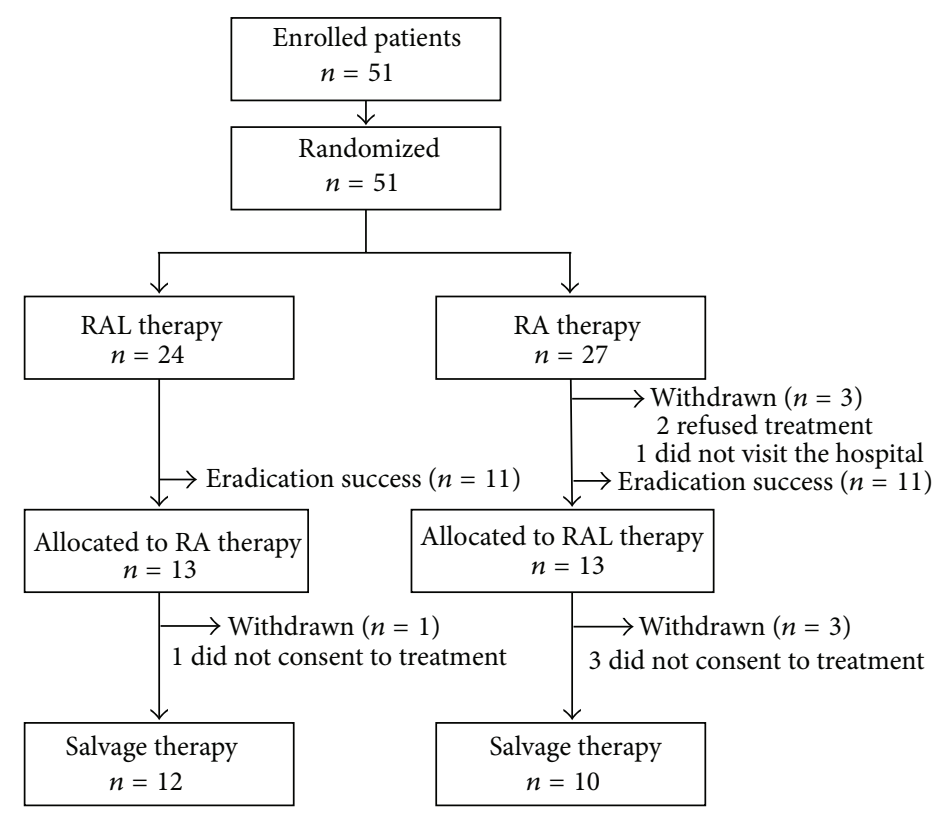

FIGURE 1: Flow diagram of the study. Enrolled patients were randomly assigned to either the RAL group, RPZ 10 mg (b.i.d.), AMPC 750 mg (b.i.d.), and LVFX $500 \mathrm{mg}$ (o.d.) for 10 days, or the RA group, RPZ $10 \mathrm{mg}$ (q.i.d.) and AMPC $500 \mathrm{mg}$ (q.i.d). Patients who failed to respond to third-line eradication therapy underwent salvage therapy.

from the per-protocol (PP) analysis because two refused treatment and one did not visit the hospital. As a result, 24 patients in each group were included in the PP analysis. $H$. pylori was eradicated from eleven patients in each group. Twelve patients in the RAL group and eleven patients in the RA group underwent salvage therapy. One patient in the RAL group and two patients in the RA group did not consent to salvage therapy. One patient in the salvage RAL group who refused treatment was excluded from PP analysis. Consequently, twelve patients in the RAL group and ten patients in the RA group were included in the PP analysis. $H$. pylori was eradicated from six patients in the RAL group (salvage RA group) and five patients in the RA group (salvage RAL group).

3.2. Backgrounds of the Patients. The backgrounds of the patients, based on PP analysis, are shown in Table 1. The two groups had similar characteristics with respect to age, sex, body mass index (BMI), reasons for the eradication, and success rate of the drug sensitivity test. The success rate of the drug sensitivity testing was defined as the ratio of number of cases with them to all cases. Four patients refused the analysis of CYP2C19. The number of CYP2C19 EM was significantly higher in the RAL group than in the RA group $(P<0.05)$.

3.3. Success Rate of the Third-Line Eradication Therapy. Drug compliance exceeded $90 \%$ for all patients included in PP analysis. The rates of eradication, based on ITT analysis, were $45.8 \%$ for the RAL group and $40.7 \%$ for the RA group and there was no significant difference $(P=0.71)$. In the PP analysis, the rates of eradication were the same $(45.8 \%)$ in both groups.
3.4. Comparison of the Patients' Backgrounds between the Success and Failure Groups in the Third-Line Eradication Therapy. Table 2 shows a comparison, based on PP analysis, of the patients' backgrounds, between the success and failure groups in the third-line eradication therapy. There was no difference with respect to sex, BMI, eradication therapy, drug resistance, and CYP2C19 polymorphism. The age (mean \pm S.D.) of the success group was $64.1 \pm 10.0$, which was significantly higher than that of the failure group $(56.2 \pm 13.5$, $P<0.05)$. The success rate of the drug sensitivity test was significantly higher for the failure group than for the success group $(80.0 \%$ versus $36.4 \%, P<0.05)$.

3.5. Salvage Therapy and Overall Eradication Rates. The rates of eradication success in salvage eradication therapy were $50.0 \%$ in the RAL group (salvage RA group) and $45.5 \%$ in the RA group (salvage RAL group), based on ITT analysis. There was no significant difference $(P=0.83)$. In PP analysis, the eradication rate was $50 \%$ in both groups. The overall eradication rate (third-line and salvage therapy eradication rate) was $73.9 \%$ in the RAL group and $64.0 \%$ in the RA group, based on ITT analysis $(P=0.46)$. In PP analysis, the overall eradication rate was $73.9 \%$ in the RAL group and $76.2 \%$ in the RA group $(P=0.86)$, which showed no significant difference (chi-square test, Figure 2).

3.6. Adverse Events. AE of the third-line eradication therapy is shown in Table 3. In both groups, the most frequently observed AE was soft stool/diarrhea (20.8\% in both groups). A rash was observed in one patient (4.2\%) in the RAL group and one patient in the RA group (4.2\%) had nausea. There was 
TABLE 1: Background of the patients based on PP analysis.

\begin{tabular}{|c|c|c|c|}
\hline & $\begin{array}{l}\text { RAL group }^{\dagger} \\
\quad(n=24)\end{array}$ & $\begin{array}{l}\text { RA group }^{\ddagger} \\
(n=24)\end{array}$ & $P$ value \\
\hline Age (mean \pm S.D.) & $57.8 \pm 12.6$ & $61.8 \pm 12.6$ & n.s. ${ }^{*}$ \\
\hline Sex (male/female) & $10 / 14$ & $8 / 16$ & n.s. ${ }^{* *}$ \\
\hline $\mathrm{BMI}^{\S}$ (mean \pm S.D.) & $23.0 \pm 3.7$ & $21.5 \pm 3.4$ & n.s. ${ }^{*}$ \\
\hline \multicolumn{4}{|l|}{ Disease, $n(\%)$} \\
\hline Gastric ulcer & $5(20.8)$ & $5(20.8)$ & n.s. ${ }^{* *}$ \\
\hline Duodenal ulcer & $3(12.5)$ & $5(20.8)$ & n.s. ${ }^{* *}$ \\
\hline Early gastric cancer & $4(16.7)$ & $3(12.5)$ & n.s. ${ }^{* *}$ \\
\hline Hyperplastic polyp & $2(8.3)$ & $0(0)$ & n.s. ${ }^{* *}$ \\
\hline Others & $10(41.7)$ & $11(45.8)$ & n.s. ${ }^{* *}$ \\
\hline $\begin{array}{l}\text { Success of } H \text {. pylori culture } \\
(\text { yes } / \text { no })^{\mathrm{a}}\end{array}$ & $17 / 7$ & $11 / 12$ & n.s. ${ }^{* *}$ \\
\hline \multicolumn{4}{|l|}{ Drug resistance, $n(\%)$} \\
\hline Amoxicillin & $0(0)$ & $0(0)$ & n.s. ${ }^{* *}$ \\
\hline Clarithromycin & $15(88.2)$ & $8(72.7)$ & n.s. ${ }^{* *}$ \\
\hline Metronidazole & $13(76.5)$ & $9(81.8)$ & n.s. ${ }^{* *}$ \\
\hline Levofloxacin & $6(35.3)$ & $7(63.6)$ & n.s. ${ }^{* *}$ \\
\hline $\begin{array}{l}\text { CYP2C19 polymorphism } \\
\left(\mathrm{EM}^{\| /} / \mathrm{PM}^{\mathrm{g}}\right)^{\mathrm{b}}\end{array}$ & $20 / 2$ & $13 / 9$ & $<0.05^{* *}$ \\
\hline
\end{tabular}

${ }^{\dagger}$ RAL group: RPZ $10 \mathrm{mg}$ (b.i.d.), AMPC $750 \mathrm{mg}$ (b.i.d.), and LVFX $500 \mathrm{mg}$ (o.d.).

${ }^{\ddagger}$ RA group: RPZ $10 \mathrm{mg}$ (q.i.d.) and AMPC $500 \mathrm{mg}$ (q.i.d.).

${ }^{\S} \mathrm{BMI}$, body mass index; ${ }^{1 \mathrm{EM}}$, extensive metabolizer; ${ }^{9} \mathrm{PM}$, poor metabolizer; ${ }^{a}$ one patient in RA group refused the drug sensitivity test; ${ }^{b}$ four patients (two in RAL group and two in RA group) refused the analysis of CYP2C19 polymorphism; ${ }^{*}$ unpaired $t$-test; ${ }^{* *}$ chi-square test.

TABLE 2: Comparison of the patients' backgrounds between the success and failure groups, based on PP analysis (third-line eradication therapy).

\begin{tabular}{|c|c|c|c|}
\hline & $\begin{array}{l}\text { Success } \\
\text { group } \\
(n=22)\end{array}$ & $\begin{array}{l}\text { Failure } \\
\text { group } \\
(n=26)\end{array}$ & $P$ value \\
\hline Age (mean \pm S.D.) & $64.1 \pm 10.0$ & $56.2 \pm 13.5$ & $<0.05^{*}$ \\
\hline Sex (male/female) & $11 / 11$ & $7 / 19$ & n.s. ${ }^{* *}$ \\
\hline $\mathrm{BMI}^{\dagger}$ (mean \pm S.D. $)$ & $22.0 \pm 3.3$ & $22.3 \pm 4.0$ & n.s. ${ }^{*}$ \\
\hline $\begin{array}{l}\text { Eradication therapy } \\
\text { (RAL/RA) }\end{array}$ & $11 / 11$ & $13 / 13$ & n.s. ${ }^{* *}$ \\
\hline $\begin{array}{l}\text { Success of } H . \text { pylori culture } \\
(\text { yes/no })^{\mathrm{a}}\end{array}$ & $8 / 14$ & $20 / 5$ & $<0.05^{* *}$ \\
\hline \multicolumn{4}{|l|}{ Drug resistance, $n(\%)$} \\
\hline Amoxicillin & $0(0)$ & $0(0)$ & n.s. ${ }^{* *}$ \\
\hline Clarithromycin & $6(75.0)$ & $17(81.0)$ & n.s. ${ }^{* *}$ \\
\hline Metronidazole & $6(75.0)$ & $16(76.2)$ & n.s. ${ }^{* *}$ \\
\hline Levofloxacin & $3(37.5)$ & $10(47.6)$ & n.s. ${ }^{* *}$ \\
\hline $\begin{array}{l}\text { CYP2C19 polymorphism } \\
\left(\mathrm{EM}^{\ddagger} / \mathrm{PM}^{\S}\right)^{\mathrm{b}}\end{array}$ & $14 / 5$ & $19 / 6$ & n.s. ${ }^{* *}$ \\
\hline
\end{tabular}


${ }^{a}$ one patient in failure group refused the drug sensitivity test; ${ }^{b}$ four patients (three in success group and one in failure group) refused the analysis of CYP2C19 polymorphism; ${ }^{*}$ unpaired $t$-test; ${ }^{* *}$ chi-square test.
TABLE 3: Adverse events of the third-line eradication therapy.

\begin{tabular}{lccc}
\hline & $\begin{array}{c}\text { RAL group }^{\dagger} \\
(n=24)\end{array}$ & $\begin{array}{c}\text { RA group }^{\ddagger} \\
(n=24)\end{array}$ & $P$ value \\
\hline Soft stool/diarrhea, $n(\%)$ & $5(20.8)$ & $5(20.8)$ & n.s. $^{*}$ \\
Nausea, $n(\%)$ & $0(0)$ & $1(4.2)$ & n.s. $^{*}$ \\
Rash, $n(\%)$ & $1(4.2)$ & $0(0)$ & n.s. $^{*}$ \\
\hline
\end{tabular}

${ }^{\dagger}$ RAL group: RPZ $10 \mathrm{mg}$ (b.i.d.), AMPC $750 \mathrm{mg}$ (b.i.d.), and LVFX $500 \mathrm{mg}$ (o.d.).

${ }^{\ddagger}$ RA group: RPZ $10 \mathrm{mg}$ (q.i.d.) and AMPC $500 \mathrm{mg}$ (q.i.d.).

${ }^{*}$ Chi-square test.

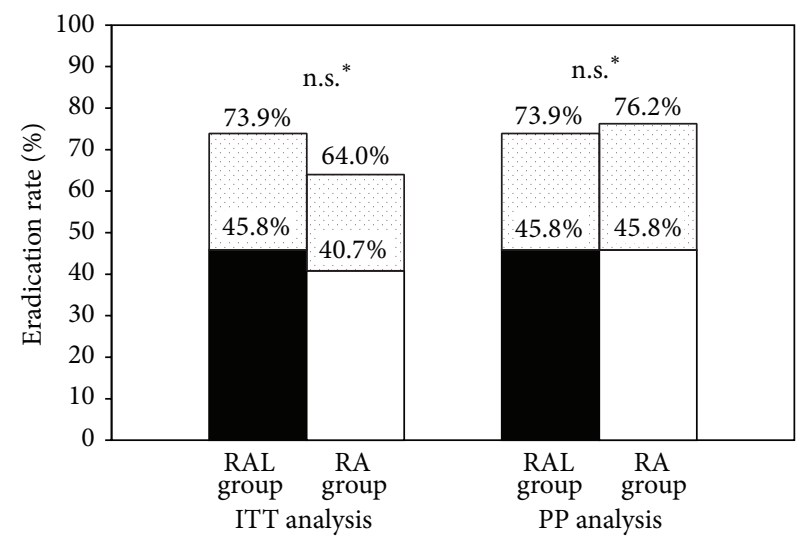

FIGURE 2: ITT and PP analysis of the overall success rate (thirdline therapy and salvage therapy eradication rate). Black and white areas indicate the success rates of third-line eradication therapy. The dotted area indicates the additional success rate of the following salvage therapy. ${ }^{*}$ Chi-square test.

no significant difference between the two groups regarding any $\mathrm{AE}$ and all $\mathrm{AE}$ were reversible.

\section{Discussion}

Recently, sitafloxacin- (STFX-) based third-line eradication therapy has been reported to be effective, with an eradication rate of $70-83.6 \%$ [11-13]. The reasons for the relatively high eradication rate might be attributable to the following factors. The DNA gyrase subunit A $(g r y \mathrm{~A})$ mutation is known to be responsible for the resistance of $H$. pylori to quinolones [14]. It was reported that the MIC (50) (MIC for $50 \%$ of the organisms) of STFX against gyrA mutants is $0.12 \mu \mathrm{g} / \mathrm{mL}$, significantly lower than that of LVFX $(8 \mu \mathrm{g} / \mathrm{mL})$ [12]. Furthermore, the $H$. pylori resistance rate to STFX was $7.7 \%$, which was lower than that of LVFX [11]. Although STFX has some benefits, it is available only in Japan and Thailand now. Taking this current state into consideration, LVFX-based triple therapy and high-dose PPI and AMPC dual therapy may be widely available in many countries, as well as in Japan. In a previous study [11], STFX-based third-line therapy was superior to that based on LVFX but the regimen requires patients to take LVFX $300 \mathrm{mg}$ (b.i.d). In our LVFX-based triple therapy, the patients take LVFX $500 \mathrm{mg}$ (o.d.). Because LVFX is dependent on concentration, our regimen makes the best use of the drug characteristics. In this study, the 
eradication rate of the RAL group was $45.8 \%$ on ITT analysis, which was almost the same as the RA group (40.7\%). The third-line RAL or RA may be inferior to STFX-based therapy.

In this study, LVFX and AMPC were selected as the antibiotics for the third-line and salvage eradication therapy. Currently, LVFX is used for a wide range of infectious diseases and is the most frequently used quinolone for $H$. pylori eradication [12]. As a result, a high percentage of $H$. pylori strains are LVFX-resistant. The resistance rate of $H$. pylori to LVFX has been reported to be $39-57 \%$ [11, 15]. In this study it was $46.4 \%$, similar to previous reports. This might have influenced the relatively low eradication rate of the RAL group. On the other hand, the resistance rate of $H$. pylori to AMPC has been reported to be low in Japan, the United States, Europe, and China [16]. Consequently the eradication rate of a high-dose PPI + AMPC regimen has been reported to be 90.9 to $100 \%$ when used as second-line eradication therapy $[17,18]$. Contrary to previous studies, Murakami et al. reported that the resistance rate of $H$. pylori to AMPC in patients who failed both first- and second-line AMPC-based eradication therapy was $8.2 \%$ and the eradication rate of a high-dose PPI + AMPC regimen as the third-line therapy was $54.3 \%$ [11]. The resistance rate was relatively high. It is possible that a proportion of $H$. pylori strains acquire resistance to AMPC during first- and second-line eradication therapy. In our study, although the rate of resistance of $H$. pylori to AMPC was $0 \%, 40.4 \%$ of the patients had failed the drug sensitivity test and, in some of these cases, AMPC-resistant $H$. pylori strains may have been present. This could be a cause of the low eradication rate ( $40.7 \%$ on ITT analysis).

Increased PPI dosing was reported to be critical for the success of $H$. pylori eradication [19]. PPI is generally metabolized in the liver by CYP2C19. In Japan, the percentages of the EM and PM genotypes of CYP2C19 are $89 \%$ and $11 \%$, respectively [20]. Lee et al. reported that patients with the PM genotype of CYP2C19 achieved a high $H$. pylori eradication rate compared to those with EM [21]. Among the many PPIs, rabeprazole is mainly reduced to rabeprazole thioether by a nonenzymatic pathway and partially metabolized to demethylated rabeprazole by CYP2C19. Therefore, its metabolism is not influenced by the CYP2C19 polymorphism [22]. Rabeprazole was used in this study and the ratio of EM did not differ significantly between the success and failure groups in third-line eradication therapy.

This study has some limitations. Firstly, the number of study patients was small. Secondly, a comparison with STFX-based therapy was not implemented. In the future, a large scale prospective study, including other suggestive regimens, should be carried out to establish standard thirdline eradication therapy for $H$. pylori. Thirdly, in spite of randomization, there exists some difference of the clinical background between RAL and RA groups. Particularly, CYP2C19 genotype showed the significant difference between RAL and RA groups. Because the success rate of $H$. pylori eradication with third-line therapy or salvage therapy did not show the difference between RAL and RA groups, we speculated that the influence of this uneven distribution might be low.

In conclusion, as the third-line triple therapy, the eradication rate with rabeprazole, AMPC, and LVFX for 10 days was equal to that with high-dose rabeprazole and AMPC for 14 days. These efficacy rates were not high but can be an alternative therapy after second-line failure because these therapies seemed free from severe adverse events.

$\begin{array}{ll}\text { Abbreviations } \\ \text { MALT: } & \text { Mucosa-associated lymphoid tissue } \\ \text { ITP: } & \text { Idiopathic thrombocytopenic purpura } \\ \text { PPI: } & \text { Proton pump inhibitor } \\ \text { AMPC: } & \text { Amoxicillin } \\ \text { CAM: } & \text { Clarithromycin } \\ \text { MNZ: } & \text { Metronidazole } \\ \text { LVFX: } & \text { Levofloxacin } \\ \text { RPZ: } & \text { Rabeprazole } \\ \text { UBT: } & \text { 13 C-urea breath test } \\ \text { CYP2C19: } & \text { Cytochrome P450 2C19 } \\ \text { MIC: } & \text { Minimum inhibitory concentrations } \\ \text { gFCS: } & \text { Gene analysis by fluorescence correlation } \\ & \text { spectroscopy } \\ \text { EM: } & \text { Extensive metabolizer } \\ \text { PM: } & \text { Poor metabolizer } \\ \text { AE: } & \text { Adverse event } \\ \text { ITT: } & \text { Intension to treat } \\ \text { PP: } & \text { Per-protocol } \\ \text { BMI: } & \text { Body mass index } \\ \text { STFX: } & \text { Sitafloxacin } \\ \text { gryA: } & \text { DNA gyrase subunit A. }\end{array}$

\section{Conflict of Interests}

The authors declare that there is no conflict of interests regarding the publication of this paper.

\section{Acknowledgment}

This study was supported by the grants from Chiba Foundation for Health Promotion and Disease Prevention.

\section{References}

[1] H. Miwa, N. Sasaki, K. Sugano et al., "Recurrent peptic ulcers in patients with following successful Helicobacter pylori eradication: a multicenter study of 4940 patients," Helicobacter, vol. 9, no. 1, pp. 9-16, 2004.

[2] N. Uemura, S. Okamoto, S. Yamamoto et al., "Helicobacter pylori infection and the development of gastric cancer," The New England Journal of Medicine, vol. 345, no. 11, pp. 784-789, 2001.

[3] T. Takahashi, T. Yujiri, K. Shinohara et al., "Molecular mimicry by Helicobacter pylori CagA protein may be involved in the pathogenesis of $H$. pylori-associated chronic idiopathic thrombocytopenic purpura," British Journal of Haematology, vol. 124, no. 1, pp. 91-96, 2004.

[4] P. Malfertheiner, F. Megraud, C. O'Morain et al., "Current concepts in the management of Helicobacter pylori infection: the Maastricht III consensus report," Gut, vol. 56, no. 6, pp. 772-781, 2007.

[5] K. Fukase, M. Kato, S. Kikuchi et al., "Effect of eradication of Helicobacter pylori on incidence of metachronous gastric 
carcinoma after endoscopic resection of early gastric cancer: an open-label, randomised controlled trial," The Lancet, vol. 372, no. 9636, pp. 392-397, 2008.

[6] M. Asaka, M. Kato, and D. Y. Graham, "Strategy for eliminating gastric cancer in Japan," Helicobacter, vol. 15, no. 6, pp. 486-490, 2010.

[7] M. Sasaki, N. Ogasawara, K. Utsumi et al., "Changes in 12-year first-line eradication rate of Helicobacter pylori based on triple therapy with proton pump inhibitor, amoxicillin and clarithromycin," Journal of Clinical Biochemistry and Nutrition, vol. 47, no. 1, pp. 53-58, 2010.

[8] T. Matsuhisa, T. Kawai, T. Masaoka et al., "Efficacy of Metronidazole as second-line drug for the treatment of Helicobacter pylori infection in the Japanese population: a multicenter study in the Tokyo metropolitan area," Helicobacter, vol. 11, no. 3, pp. 152-158, 2006.

[9] D. Asaoka, A. Nagahara, and T. Matsuhisa, "Trends of secondline eradication therapy for Helicobacter pylori in Japan: a multicenter study in the Tokyo metropolitan area," Helicobacter, vol. 18, no. 6, pp. 468-472, 2013.

[10] T. Rokkas, P. Sechopoulos, I. Robotis, G. Margantinis, and D. Pistiolas, "Cumulative H. pylori eradication rates in clinical practice by adopting first and second-line regimens proposed by the maastricht III consensus and a third-line empirical regimen," The American Journal of Gastroenterology, vol. 104, no. 1, pp. 21-25, 2009.

[11] K. Murakami, T. Furuta, T. Ando et al., "Multi-center randomized controlled study to establish the standard third-line regimen for Helicobacter pylori eradication in Japan," Journal of Gastroenterology, vol. 48, no. 10, pp. 1128-1135, 2013.

[12] Y. Hirata, T. Ohmae, A. Yanai et al., "Sitafloxacin resistance in Helicobacter pylori isolates and sitafloxacin-based triple therapy as a third-line regimen in Japan," International Journal of Antimicrobial Agents, vol. 39, no. 4, pp. 352-355, 2012.

[13] J. Matsuzaki, H. Suzuki, T. Nishizawa et al., "Efficacy of sitafloxacin-based rescue therapy for Helicobacter pylori after failures of first- and second-line therapies," Antimicrobial Agents and Chemotherapy, vol. 56, no. 3, pp. 1643-1645, 2012.

[14] J. Tankovic, C. Lascols, Q. Sculo, J.-C. Petit, and C.-J. Soussy, "Single and double mutations in gyrA but not in gyrB are associated with low- and high-level fluoroquinolone resistance in Helicobacter pylori," Antimicrobial Agents and Chemotherapy, vol. 47, no. 12, pp. 3942-3944, 2003.

[15] K. Murakami, T. Okimoto, M. Kodama et al., "Sitafloxacin activity against Helicobacter pylori isolates, including those with gyrA mutations," Antimicrobial Agents and Chemotherapy, vol. 53, no. 7, pp. 3097-3099, 2009.

[16] M. Song and T. L. Ang, "Second and third line treatment options for Helicobacter pylori eradication," World Journal of Gastroenterology, vol. 20, no. 6, pp. 1517-1528, 2014.

[17] T. Furuta, N. Shirai, F. Xiao et al., "High-dose rabeprazole/ amoxicillin therapy as the second-line regimen after failure to eradicate $H$. pylori by triple therapy with the usual doses of a proton pump inhibitor, clarithromycin and amoxicillin," Hepato-Gastroenterology, vol. 50, no. 54, pp. 2274-2278, 2003.

[18] N. Shirai, M. Sugimoto, C. Kodaira et al., "Dual therapy with high doses of rabeprazole and amoxicillin versus triple therapy with rabeprazole, amoxicillin, and metronidazole as a rescue regimen for Helicobacter pylori infection after the standard triple therapy," European Journal of Clinical Pharmacology, vol. 63, no. 8, pp. 743-749, 2007.
[19] K.-L. Goh, J. Manikam, and C.-S. Qua, "High-dose rabeprazoleamoxicillin dual therapy and rabeprazole triple therapy with amoxicillin and levofloxacin for 2 weeks as first and second line rescue therapies for Helicobacter pylori treatment failures," Alimentary Pharmacology \& Therapeutics, vol. 35, no. 9, pp. 1097-1102, 2012.

[20] T. Furuta, N. Shirai, M. Kodaira et al., "Pharmacogenomicsbased tailored versus standard therapeutic regimen for eradication of H. pylori," Clinical Pharmacology \& Therapeutics, vol. 81, no. 4, pp. 521-528, 2007.

[21] J. Y. Lee, N. Kim, M. S. Kim et al., "Factors affecting first-line triple therapy of Helicobacter pylori including CYP2C19 genotype and antibiotic resistance," Digestive Diseases and Sciences, vol. 59, pp. 1235-1243, 2014.

[22] T. Furuta, N. Shirai, M. Takashima et al., "Effects of genotypic differences in CYP2C19 status on cure rates for Helicobacter pylori infection by dual therapy with rabeprazole plus amoxicillin," Pharmacogenetics, vol. 11, no. 4, pp. 341-348, 2001. 




The Scientific World Journal
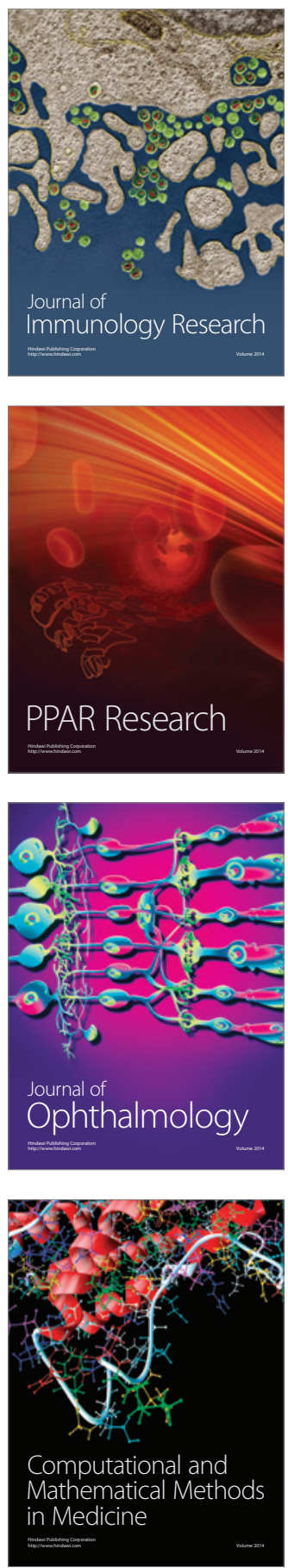

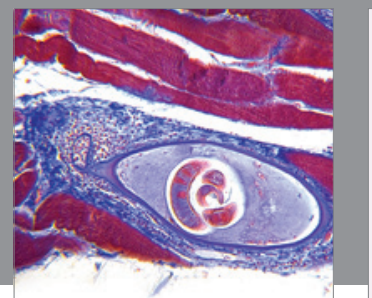

Gastroenterology

Research and Practice


\section{Hindawi}

Submit your manuscripts at

http://www.hindawi.com
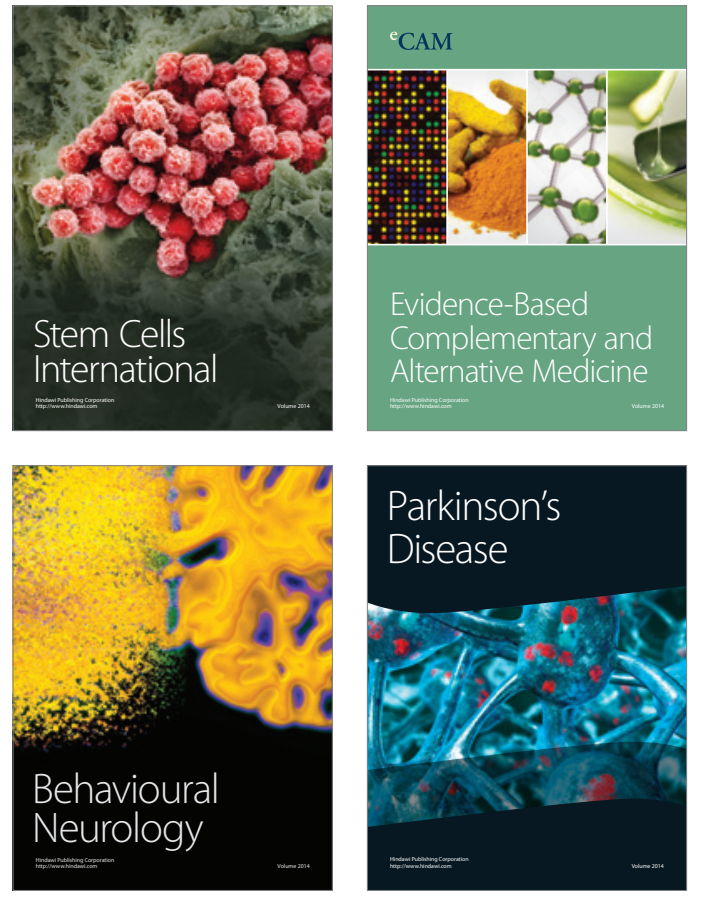
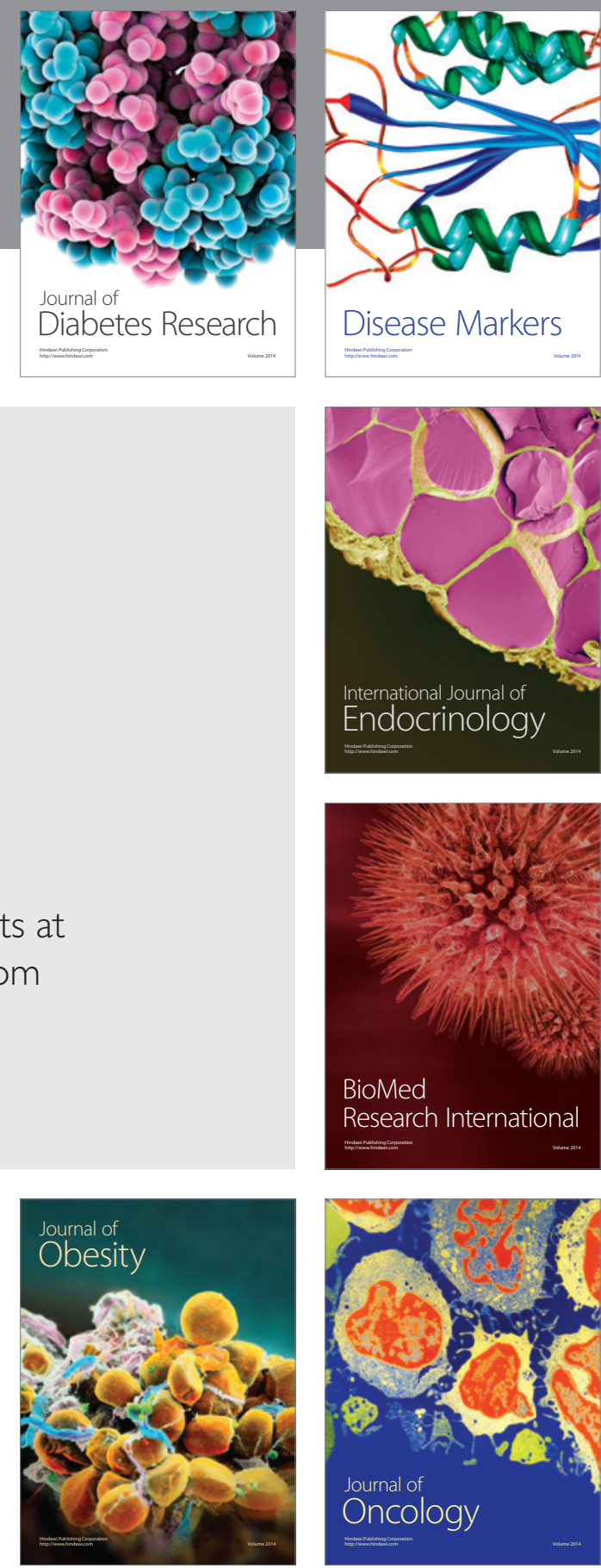

Disease Markers
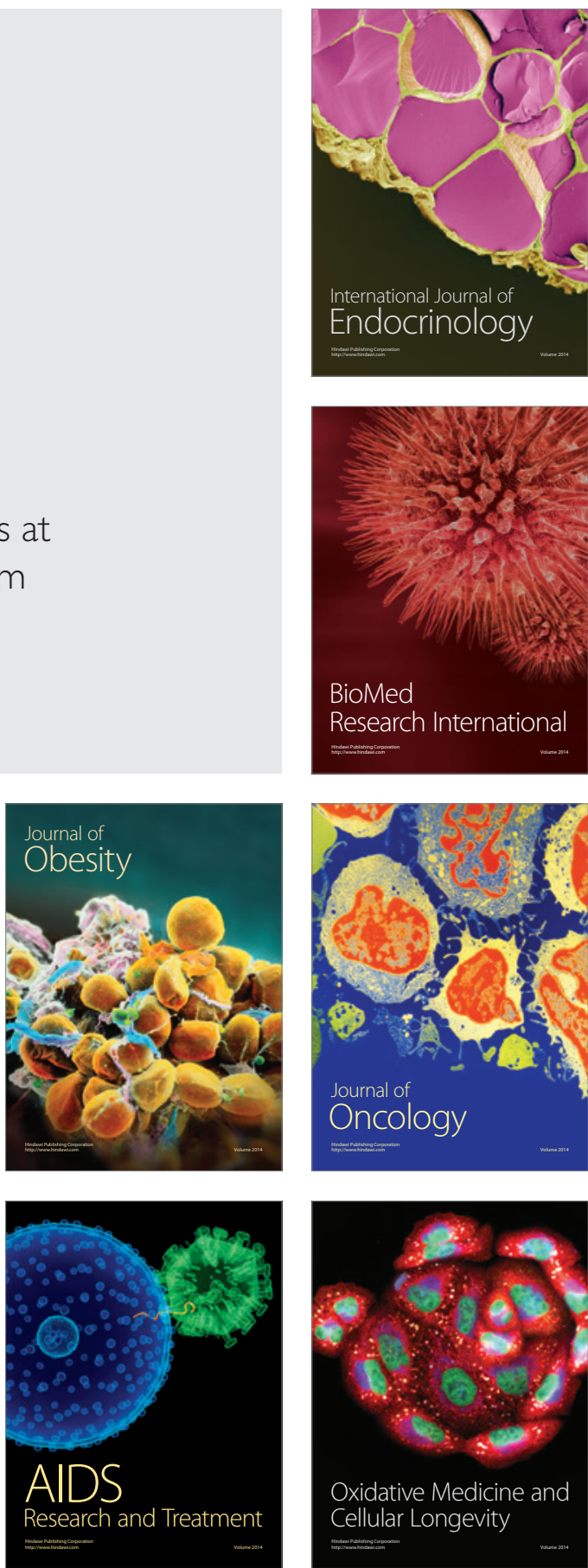